World Maritime University

The Maritime Commons: Digital Repository of the World Maritime University

\title{
An evaluation of MAAP's Train the Simulator Trainer and Assessor (IMO Model Course 6.10): trainees' perspectives and reverberations
}

\author{
Lester C. Malabanan \\ Maritime Academy of Asia and the Pacific \\ Leonora T. Dela Cruz \\ Maritime Academy of Asia and the Pacific
}

Follow this and additional works at: https://commons.wmu.se/imla2021

Part of the Education Commons

\section{Recommended Citation}

Malabanan, L. C.\& Dela Cruz, L. T. (2021). An evaluation of MAAP's Train the Simulator Trainer and Assessor (IMO Model Course 6.10): trainees' perspectives and reverberations. In Pazaver, A., Manuel, M. E., Bolmsten, J., Kitada, M., Bartuseviciene, I. (Eds.), Proceedings of the International Maritime Lecturers' Association. Seas of transition: setting a course for the future (pp. 113-121). World Maritime University. http://dx.doi.org/10.21677/imla2021.11

This Paper is brought to you courtesy of Maritime Commons. Open Access items may be downloaded for noncommercial, fair use academic purposes. No items may be hosted on another server or web site without express written permission from the World Maritime University. For more information, please contact library@wmu.se. 
http://dx.doi.org/10.21677/imla2021.11

\title{
An evaluation of MAAP's Train the Simulator Trainer and Assessor (IMO Model Course 6.10): Trainees' perspectives and reverberations
}

\author{
Lester C. Malabanan \\ Captain, Maritime Academy of Asia and the Pacific, Bataan, Philippines, \\ lestermalabanan07@gmail.com \\ Leonora T. Dela Cruz, Ph.D. \\ Professor, Maritime Academy of Asia and the Pacific, Bataan, Philippines, \\ delacruzleonor29@gmail.com
}

\begin{abstract}
The study aims to analyze how the trainees evaluate the "Train the simulator trainer and assessor" (IMO Model Course 6.10) provided by the Maritime Academy of Asia and the Pacific (MAAP) for free in cooperation with the Maritime Industry Authority (MARINA) and the Commission on Higher Education (CHED). The training is regularly rendered as one of the extension services of MAAP. The study utilized the data from the evaluation form accomplished by the eight batches corresponding to 94 trainees in 2019. Results showed that the trainees regarded the training as "Excellent" in terms of the General Information. The trainees likewise rated the training as "Excellent" in terms of the Topics/Exercises. Statistics showed that there was no significant difference between the evaluation of the trainees on the training on IMO Model Course 6.10 when they are grouped according to batches both in General Information and Topics/Exercises.
\end{abstract}

Keywords: Evaluation, IMO Model Course 6.10, General Information, Topics/Exercises

\section{Introduction}

Maritime education and training are universally carried out through simulations. Simulators have become the primary tools for shipboard education and training. Numerous research and position papers described the importance of simulators. Ecdisorg (2017) mentioned that maritime simulators are now the modern way to gain competence. Sendi (2015), on the other hand, claimed that maritime training simulators at all events are valuable instructional and pedagogical tools. The conduct of simulation training helps to prevent marine accidents and environmental pollution (Salman, 2013).

There are two performance standards concerning Maritime simulators: applying to simulators used for training, and for simulators used to assess competence. (ecdisorg, 2017)

Simulation is the most significant and innovative advancement in maritime training to date. Maritime training and education professionals use simulation to train and assess mariners on a variety of technical skills, such as navigation, rules of the road, and ship handling. It is widely held to be the most effective method of teaching non-technical skills like information 
processing, situational awareness, decision making, judgment, leadership, teamwork, communication, multitasking, and stress and fatigue management. (Huhnke, n. d.)

Khodayari (n. d.) enumerated reasons why simulation is useful. They are as follows: simulation involve and motivate learners; it improves the capability to connect learning to real-life scenarios; it provides freedom to experiment with new behaviors in a risk-free environment; it provides opportunity for immediate feedback from actions taken and decisions made; no damages and no expenses incurred due to making mistakes, and it enhances the ability to teach teamwork and leadership.

The Maritime Industry Authority (MARINA) and the Commission on Higher Education (CHED), in full cooperation with the Maritime Academy of Asia and the Pacific (MAAP), conduct the Train the simulator trainer and assessor course (IMO Model Course 6.10). This forms part of the Administration-approved requirements for simulator instructors and assessors. MAAP provides the training course for free as one of its extension services regularly rendered. (MARINA STCW Advisory No. 2017-09)

The training on IMO Model Course 6.10 aims to train the simulator trainers and assessors. The training course was developed by IMO through the Sub-Committee of Standard of Training and Watchkeeping. The course was adapted to maximize the usage of MAAP Type A, B, C and S simulators. (IMO Model Course 6.10 Course Manual)

The scope of the training course is to establish a reliable simulator training program for the instructor to impart comprehensive simulator training to the seafarer that will include the amalgamation of classroom teaching, simulation training, special working environment onboard a ship and human element, and psychology of learning. The training course also aims to foster sustainable training skills to the instructor within the changing maritime environment. Furthermore, it intends the trainees to acquire simulator training skills that include the psychology of learning. (IMO Model Course 6.10 Course Manual)

They are posted on the website of the National Academic Press (NAP) that the role and qualification of marine simulator instructors evoke considerable discussion and debate. Some people in the marine simulator field believe the instructor is the most crucial training element; others believe the trainee is the most essential part of the simulation because beneficial changes in trainee behavior and performance are the desired product. A third view is that the simulator and the simulation produced are particularly important.

Asghar Ali (2006) conducted a study that examined the use of the marine simulator and future perspective, and in parallel how the importance of simulator instructors is on the rise. His dissertation emphasized that existing tools available for the qualification of the simulator instructor need to be augmented with new measures so as to show the quality of the simulatorbased training. Only through these measures, effective and efficient preparation of the seafarers can be achieved in line with training objectives of the STCW Convention.

This research was conducted to analyze the trainees' responses on the Training Course Evaluation Form administered at the end of every series of Train the Simulator Trainer and Assessor (IMO Model Course 6.10) provided by MAAP. The evaluation form provides an assessment of the Model Course and can serve as the basis for any future improvements or adjustments. 
It is essential to periodically assess and adapt your activities to ensure they are as effective as they can be. Evaluation can help you identify areas for improvement and ultimately help you realize your goals more efficiently. Evaluation enables you to demonstrate your program's success or progress. The information you collect allows you to better communicate your program's impact on others, which is critical for public relations, staff morale, and attracting and retaining support from current and potential funders. (meera, n. d.)

The primary purpose of evaluating a training program is to gain knowledge about whether it has achieved or failed its objectives. Analyzing the training event by using appropriate evaluation tools can improve the outcome of future training to a considerable extend. Even if the evaluation process of training is essential, it must always be incorporated within the available framework of time and cost. Defining the appropriate questions is the key starting point of every evaluation. (Keller, Stefanie, n. d.)

The main problem of the study was, "How may the trainees evaluate IMO Model Course 6.10"? Specifically, it sought answers to the following questions:

1. How may the trainees evaluate MAAP's Train the Simulator Trainer and Assessor (IMO Model Course 6.10) in terms of the General Information given in the training?

2. How may the trainees evaluate MAAP's Train the Simulator Trainer and Assessor (IMO Model Course 6.10) in terms of Topics/Exercises?

3. Is there a significant difference between the evaluation of the trainees of MAAP's Train the Simulator Trainer and Assessor (IMO Model Course 6.10) when grouped according to batches?

The hypothesis tested in the study was, "There is no significant difference between the evaluation of the trainees of MAAP's Train the Simulator Trainer and Assessor (IMO Model Course 6.10) when grouped according to batches."

\section{Methods}

The study utilized the document analysis approach. It made use of the Training Course Evaluation Form accomplished by the trainees at the end of every IMO Model Course 6.10. The evaluation form consists of two parts. Part A is the evaluation of the trainees on the General Information of IMO Model Course 6.10 and Part B is the assessment of the trainees on the topics/exercises given in the model course.

The responses of the respondents were interpreted using the following scale:

$\begin{array}{ll}\text { Point } & \text { Descriptive Equivalent } \\ 5 & \text { Excellent } \\ 4 & \text { Very Satisfactory } \\ 3 & \text { Satisfactory } \\ 2 & \text { Fair } \\ 1 & \text { Poor }\end{array}$

The study covered the eight batches of the IMO Model Course 6.10 in 2019. These batches were $47,48,49,50,51,52,53$, and 54 . Table 1 presents the breakdown of the frequency and percentage of the respondents per batch. 
Table 1.

Frequency and Percentage Distribution of the Respondents per batch

\begin{tabular}{|l|l|l|}
\hline Batch & Frequency & Percentage \\
\hline Batch 47 & 12 & 12.77 \\
\hline Batch 48 & 12 & 12.77 \\
\hline Batch 49 & 13 & 13.83 \\
\hline Batch 50 & 12 & 12.77 \\
\hline Batch 51 & 8 & 8.51 \\
\hline Batch 52 & 10 & 10.63 \\
\hline Batch 53 & 14 & 14.89 \\
\hline Batch 54 & 13 & 13.83 \\
\hline Total & $\mathbf{9 4}$ & $\mathbf{1 0 0}$ \\
\hline
\end{tabular}

The data presented in Table 1 show that the highest number of respondents was of batch 53, with 14 trainees corresponding to 14.89 percent. The lowest frequency of respondents was of batch 51 , with only eight (8) trainees representing 8.51 percent of the respondents. Batches 49 and 54 have the same frequency of respondents or 13 trainees; batches 47, 48, and 50 each have 12 trainees; and batch 52 contributed ten (10) respondents equivalent to 10.63 percent.

\section{Results and Discussion}

This part presents the summary of the data collected accompanied by an interpretation in an attempt to answer the problem of the study.

Table 2 presents the frequency distribution of the responses of the trainees on the IMO Model Course 6.10 evaluation on General Information.

Table 2.

Frequency Distribution of Responses on Evaluation of IMO Model Course 6.10 in terms of General Information

\begin{tabular}{|l|l|l|l|l|l|l|l|}
\hline & $\mathbf{5}$ & $\mathbf{4}$ & $\mathbf{3}$ & $\mathbf{2}$ & $\mathbf{1}$ & $\mathbf{M e a n}$ & $\begin{array}{l}\text { Descriptive } \\
\text { Equivalent }\end{array}$ \\
\hline $\begin{array}{l}\text { 1. The course was suitable for the } \\
\text { attainment of the objective of the program. }\end{array}$ & 64 & 28 & 2 & 0 & 0 & $\mathbf{4 . 6 4}$ & Excellent \\
\hline $\begin{array}{l}\text { 2. There was adequate/sufficient teaching } \\
\text { facilities/laboratory equipment which is } \\
\text { readily available }\end{array}$ & 72 & 20 & 2 & 0 & 0 & $\mathbf{4 . 7 2}$ & Excellent \\
\hline $\begin{array}{l}\text { 3. The course was taught with appropriate } \\
\text { and available textbooks references and hand- } \\
\text { outs/handbooks. }\end{array}$ & 64 & 27 & 3 & 0 & 0 & $\mathbf{4 . 6 2}$ & Excellent \\
\hline $\begin{array}{l}\text { 4. The length of time of the course was } \\
\text { suitable to meet all the requirements of the } \\
\text { training. }\end{array}$ & 60 & 33 & 1 & 0 & 0 & $\mathbf{4 . 6 2}$ & Excellent \\
\hline $\begin{array}{l}\text { 5. The theoretical aspect and the practical } \\
\text { application of the course were logically } \\
\text { sequenced. }\end{array}$ & 64 & 27 & 3 & 0 & 0 & $\mathbf{4 . 6 2}$ & Excellent \\
\hline
\end{tabular}




\begin{tabular}{|l|l|l|l|l|l|l|l|l|}
\hline $\begin{array}{l}\text { 6. The content of the course covers all the } \\
\text { required/necessary topics/requirement of the } \\
\text { training. }\end{array}$ & 61 & 31 & 2 & 0 & 0 & $\mathbf{4 . 6 1}$ & Excellent \\
\hline $\begin{array}{l}\text { 7. Instructions on the procedure for each } \\
\text { laboratory/practicum were clearly emphasized. }\end{array}$ & 70 & 23 & 1 & 0 & 0 & $\mathbf{4 . 7 2}$ & Excellent \\
\hline $\begin{array}{l}\text { 8. The practicum site and necessary } \\
\text { equipment was readily setup before conduct of } \\
\text { practicum exercises. }\end{array}$ & 69 & 22 & 3 & 0 & 0 & $\mathbf{4 . 6 7}$ & Excellent \\
\hline $\begin{array}{l}\text { 9. Practicum performed reflected the } \\
\text { application of the concepts learned. }\end{array}$ & 70 & 22 & 2 & 0 & 0 & $\mathbf{4 . 7 0}$ & Excellent \\
\hline $\begin{array}{l}\text { 10.All the topics covered by the course were } \\
\text { relevant and applicable to our present job. }\end{array}$ & 61 & 31 & 2 & 0 & 0 & $\mathbf{4 . 6 1}$ & Excellent \\
\hline OVERALL MEAN & & & & & & \\
\hline
\end{tabular}

The respondents' highest mean rating for the IMO Model Course 6.10 evaluation in terms of General Information was 7.2 interpreted as "Excellent" to both items 2 and 7. The lowest mean evaluation rating, on the other hand, was 4.61, also interpreted as "Excellent" for both items 6 and 10. The overall mean score of the respondents was 4.56 interpreted as "Excellent." Hence, the respondents rated the IMO Model Course 6.10 evaluation in terms of General Information as "Excellent."

Table 3 presents the mean rating of the respondents on the IMO Model Course 6.10 evaluation on General Information per batch.

Table 3.

Average Ratings on General Information per Batch (Batches $=8$ )

\begin{tabular}{|c|c|c|c|c|c|c|c|c|}
\hline & B47 & B48 & B49 & B50 & B51 & B52 & B53 & B54 \\
\hline $\begin{array}{l}\text { 1. The course was suitable for the } \\
\text { attainment of the objective of the } \\
\text { program. }\end{array}$ & 4.67 & 4.58 & 4.38 & 4.75 & 4.88 & 4.90 & 4.98 & 4.31 \\
\hline $\begin{array}{l}2 . \quad \text { There was adequate/sufficient } \\
\text { teaching facilities/laboratory equipment } \\
\text { which is readily available }\end{array}$ & 4.83 & 4.67 & 4.54 & 4.74 & 4.75 & 4.80 & 4.86 & 4.77 \\
\hline $\begin{array}{l}\text { 3. The course was taught with } \\
\text { appropriate and available textbooks } \\
\text { references and hand-outs/handbooks. }\end{array}$ & 4.33 & 4.58 & 4.62 & 4.50 & 4.88 & 4.70 & 4.86 & 4.77 \\
\hline $\begin{array}{l}\text { 4. The length of time of the course } \\
\text { was suitable to meet all the } \\
\text { requirements of the training. }\end{array}$ & 4.50 & 4.58 & 4.54 & 4.58 & 4.63 & 4.60 & 4.79 & 4.77 \\
\hline $\begin{array}{l}5 . \quad \text { The theoretical aspect and the } \\
\text { practical application of the course were } \\
\text { logically sequenced. }\end{array}$ & 4.42 & 4.67 & 4.46 & 4.58 & 4.63 & 4.80 & 4.79 & 4.85 \\
\hline $\begin{array}{l}\text { 6. The content of the course covers } \\
\text { all the required/necessary } \\
\text { topics/requirement of the training. }\end{array}$ & 4.42 & 4.50 & 4.46 & 4.58 & 4.88 & 4.60 & 4.86 & 4.77 \\
\hline $\begin{array}{l}\text { 7. Instructions on the procedure } \\
\text { for each laboratory/practicum were } \\
\text { clearly emphasized. }\end{array}$ & 4.75 & 4.50 & 4.54 & 4.83 & 4.88 & 4.60 & 4.93 & 4.85 \\
\hline
\end{tabular}




\begin{tabular}{|c|c|c|c|c|c|c|c|c|}
\hline $\begin{array}{l}8 . \quad \text { The practicum site and } \\
\text { necessary equipment was readily setup } \\
\text { before conduct of practicum exercises. }\end{array}$ & 4.58 & 4.67 & 4.54 & 4.50 & 4.75 & 4.90 & 4.93 & 4.77 \\
\hline $\begin{array}{l}\text { 9. Practicum performed reflected } \\
\text { the application of the concepts learned. }\end{array}$ & 4.75 & 4.75 & 4.46 & 4.75 & 4.75 & 4.60 & 4.86 & 4.85 \\
\hline $\begin{array}{l}\text { 10. All the topics covered by the } \\
\text { course were relevant and applicable to } \\
\text { our present job. }\end{array}$ & 4.58 & 4.50 & 4.54 & 4.67 & 4.63 & 4.80 & 4.86 & 4.3 \\
\hline Mean Ratings & 4.58 & 4.60 & 4.51 & 4.65 & 4.77 & 4.73 & 4.87 & 4.71 \\
\hline
\end{tabular}

The highest rating on the IMO Model Course 6.10 evaluation in terms of General Information was 4.87 , which was given by batch 53 , followed by 4.77 batch 51 . Meanwhile, batch 49 gave the lowest rating of 4.51 .

A non-parametric Friedman Test of differences in the ratings among the eight batches of trainees in terms of General Information given in the training provided by MAAP was conducted. The test is done using the IBM SPSS. Results show that there was no significant difference between the ratings by the eight batches of trainees of 'Train the Simulator Trainer and Assessor' (IMO Model Course 6.10) provided by MAAP in terms of the General Information given in the training, $X^{2}(7)=5.155, \mathrm{p}=.641$.

Table 4 presents the frequency distribution of the responses of the trainees on the IMO Model Course 6.10 evaluation on topics/exercises.

Table 4.

Frequency Distribution of Responses on Evaluation of IMO Model Course 6.10 in terms of Topics/Exercises

\begin{tabular}{|c|c|c|c|c|c|c|c|}
\hline & 5 & 4 & 3 & 2 & 1 & Mean & $\begin{array}{l}\text { Descriptive } \\
\text { Equivalent }\end{array}$ \\
\hline $\begin{array}{l}\text { 1. Introduction to Simulator \& Its } \\
\text { Importance }\end{array}$ & 64 & 30 & 0 & 0 & 0 & 4.68 & Excellent \\
\hline $\begin{array}{lcc}2 . & \text { Types of Simulators, } & \text { Design, } \\
\text { Configuration \& Classification } & \\
\end{array}$ & 67 & 23 & 4 & 0 & 0 & 4.67 & Excellent \\
\hline $\begin{array}{l}\text { 3. STCW } 2010 \& \text { Simulator Training in } \\
\text { the Philippines }\end{array}$ & 68 & 23 & 3 & 0 & 0 & 4.69 & Excellent \\
\hline 4. $\quad$ Simulator Familiarization & 63 & 27 & 4 & 0 & 0 & 4.63 & Excellent \\
\hline $\begin{array}{l}\text { 5. Conceptualizing and Planning a } \\
\text { Simulation Program }\end{array}$ & 62 & 30 & 2 & 0 & 0 & 4.64 & Excellent \\
\hline $\begin{array}{l}\text { 6. The Simulator Instructor \& Effective } \\
\text { Interpersonal and Communication }\end{array}$ & 66 & 25 & 3 & 0 & 0 & 4.67 & Excellent \\
\hline 7. $\quad$ Conducting a Simulation Exercise & 68 & 25 & 1 & 0 & 0 & 4.71 & Excellent \\
\hline $\begin{array}{l}\text { 8. Assessment, Evaluation } \\
\text { Verification }\end{array}$ & 59 & 34 & 1 & 0 & 0 & 4.62 & Excellent \\
\hline $\begin{array}{l}\text { 9. Practicum: Conduct } \\
\text { Exercises/ Assessment }\end{array}$ & 67 & 27 & 0 & 0 & 0 & 4.71 & Excellent \\
\hline OVERALL MEAN & & & & & & 4.67 & ellent \\
\hline
\end{tabular}


The respondents' highest mean rating for the IMO Model Course 6.10 evaluation in terms of Topics/Exercises was 4.71 interpreted as "Excellent" both for items 7 and 9. The lowest mean evaluation rating, on the other hand, was 4.62, also interpreted as "Excellent" for item 8. The overall mean score of the respondents was 4.67 interpreted as "Excellent." Hence, the respondents rated the IMO Model Course 6.10 evaluation in terms of Topics/Exercises as "Excellent."

Table 5 presents the mean rating of the respondents on the IMO Model Course 6.10 evaluation on Topics/Exercises per batch.

Table 5.

Average Ratings on Topics/Exercises per Batch (Batches $=8$ )

\begin{tabular}{|c|c|c|c|c|c|c|c|c|}
\hline & B47 & B48 & B49 & B50 & B51 & B52 & B53 & B54 \\
\hline $\begin{array}{l}\text { 1. Introduction } \\
\text { Simulator } \quad \& \quad \text { Its } \\
\text { Importance }\end{array}$ & 4.75 & 4.58 & 4.54 & 4.83 & 4.75 & 4.40 & 4.79 & 4.77 \\
\hline $\begin{array}{lr}2 . \quad \text { Types } & \text { of } \\
\text { Simulator, } & \text { Design, } \\
\text { Configuration } & \& \\
\text { Classification } & \\
\end{array}$ & 4.58 & 4.58 & 4.54 & 4.67 & 4.75 & 4.60 & 4.79 & 4.85 \\
\hline $\begin{array}{l}\text { 3. STCW } 2010 \& \\
\text { Simulator Training in the } \\
\text { Philippines }\end{array}$ & 4.67 & 4.67 & 4.46 & 4.67 & 4.75 & 4.80 & 4.79 & 4.77 \\
\hline $\begin{array}{l}4 . \quad \text { Simulator } \\
\text { Familiarization }\end{array}$ & 4.50 & 4.67 & 4.31 & 4.75 & 4.75 & 4.50 & 4.79 & 4.77 \\
\hline $\begin{array}{l}5 . \quad \text { Conceptualizing } \\
\text { and Planning a Simulation } \\
\text { Program }\end{array}$ & 4.67 & 4.58 & 4.46 & 4.58 & 4.63 & 4.80 & 4.71 & 4.69 \\
\hline $\begin{array}{lr}6 . \quad \text { The } & \text { Simulator } \\
\text { Instructor \& } & \text { Effective } \\
\text { Interpersonal } & \text { and } \\
\text { Communication } & \end{array}$ & 4.42 & 4.58 & 4.46 & 4.58 & 4.88 & 4.80 & 4.86 & 4.85 \\
\hline $\begin{array}{l}\text { 7. Conducting } \\
\text { Simulation Exercise }\end{array}$ & 4.75 & 4.50 & 4.69 & 4.67 & 4.88 & 4.60 & 4.86 & 4.77 \\
\hline $\begin{array}{l}8 . \quad \text { Assessment, } \\
\text { Evaluation } \\
\text { Verification }\end{array}$ & 4.67 & 4.50 & 4.54 & 4.58 & 4.50 & 4.70 & 4.71 & 4.69 \\
\hline $\begin{array}{l}\text { 9. Practicum: } \\
\text { Conduct } \quad \text { Simulation } \\
\text { Exercises/ }\end{array}$ & 4.67 & 4.50 & 4.62 & 4.75 & 4.75 & 4.80 & 4.79 & 4.85 \\
\hline Mean Ratings & 4.63 & 4.57 & 4.51 & 4.68 & 4.74 & 4.67 & 4.79 & 4.78 \\
\hline
\end{tabular}

The highest rating on the IMO Model Course 6.10 evaluation in terms of Topics/Exercises was 4.79 , which was given by batch 53 , followed by 4.78 by batch 54 . On the other hand, batch 49 gave the lowest rating of 4.57 .

A non-parametric Friedman Test of differences in the ratings among the eight batches of trainees in terms of Topics/Exercises given in the training provided by MAAP was conducted. The test is done using the IBM SPSS. Results show that there was no significant difference 
between the ratings by the eight batches of trainees of 'Train the Simulator Trainer and Assessor' (IMO Model Course 6.10) provided by MAAP in terms of the Topics/Exercises given in the training, $\mathrm{X}^{2}(7)=6.051, \mathrm{p}=.534$.

\section{Findings}

In light of the results presented earlier, the following findings were enumerated

1. The mean rating given by the respondents on their evaluation of the MAAP's Train the Simulator Trainer and Assessor (IMO Model Course 6.10) in terms of General Information is 4.65 interpreted as "Excellent."

2. The mean rating given by the respondents on their evaluation of the MAAP's Train the Simulator Trainer and Assessor (IMO Model Course 6.10) in terms of Topics/Exercises is 4.67 interpreted as "Excellent."

3. There is no significant difference between the ratings of the respondents on MAAP's Train the Simulator Trainer and Assessor (IMO Model Course 6.10) in terms of General Information among the eight batches of respondents.

4. There is no significant difference between the ratings of the respondents on MAAP's Train the Simulator Trainer and Assessor (IMO Model Course 6.10) in terms of Topics/Exercises among the eight batches of respondents.,

\section{Conclusions and Recommendations}

In accordance with the findings presented earlier, the following conclusions were formulated

1. The "Train the simulator trainer and assessor" (IMO Model Course 6.10) offered by MAAP is "Excellent" both in terms of General Information and in terms of Topics/Exercises as evaluated by the trainees.

2. The respondents grouped according to batches have statistically the same ratings on the MAAP IMO Model Course 6.10 training in terms of General information.

3. The respondents grouped according to batches have statistically the same ratings on the training in terms of Topics/Exercises.

Based on the findings and conclusions of the study, the following recommendations were formulated

1. The trainees rated the training provided by MAAP on the IMO Model Course 6.10 as "Excellent" both in terms of General Information and Topics/Exercises. Hence, it is recommended that MAAP continues to provide the training for free in cooperation with CHED and MARINA as its regular extension service and as part of its objective to maximize the usage of MAAP Type A, B, C and S simulators.

2. Since the training on the IMO Model Course 6.10 is being done several times per year, it would be helpful to come up with an online evaluation procedure. 
3. To maximize the training provided by MAAP on the IMO Model Course 6.10 it is recommended to have equal numbers of Deck and Engine participants.

4. Future researchers can study the training provided by MAAP on the IMO Model Course 6.10 in terms of other variables satisfactory and effectiveness.

\section{References}

Asghar Ali (2006). Role and Importance of Simulator Instructor. Retrieved from https://pdfs.semanticscholar.org/d14d/fc036618a08a021d36c8f552497c20927e8f.pdf

ecdisorg (2017). Virtual reality: Maritime Simulators Training for Seafarers. Retrieved from https:/www.nauticalsimulation.com/virtual-reality-maritime-simulators-training-seafarers/

Huhnke, Marie (n. d.). Learning Through Simulation: Maritime Simulation from an Educator's perspective. Retrieved from http://digitaleditions.walsworthprintgroup.com/publication/? $\mathrm{i}=408860 \&$ article_id $=2786440 \&$ view=articleBrowser\# $\{\% 22$ issue_id $\% 22: 408860, \% 22$ view $\% 22: \% 22$ articleBrowser $\% 22, \% 22$ article_id $\% 22: \% 222786440 \% 22\}$

Keller, Stefanie (n. d.). Training Evaluation. Retrieved from https://sswm.info/traintrainers/post-training-activities/training-evaluation

Khodayari, Shahrokh (n. d.). Simulation in Maritime Education andTraining. Retrieved from https://www.he-alert.org/filemanager/root/site_assets/standalone_article_pdfs_1220/he01375.pdf

meera.snre.umich.edu (n. d.). Evaluation: What is it and why do it? Retrieved from http://meera.snre.umich.edu/evaluation-what-it-and-why-do-it

MARINA STCW Advisory No. 2017-09. Retrieved from http://www.jpmac.or.jp/img/research/pdf_seamanlaw/M81_stcw-a-2017-09.pdf

NAP. Effective Training with Simulation: The Instructional Design Process. Retrieved from https://www.nap.edu/read/5065/chapter/5\#68

Send, Yaser H. IIntegrated Maritime Simulation Complex Management, Quality and Training Effectiveness from the Perspective of Modeling and Simulation in the State of Florida, USA (A Case Study). $\quad$ Retrieved from http://etd.fcla.edu/CF/CFE0005999/Sendi_Yaser_H_2015_Thesis-Final_Submission.pdf 